\title{
FORMULASI GEL EKSTRAK PATIKAN KEBO (Euphorbia hirta L.) DAN UJI AKTIVITAS TERHADAP BAKTERI Staphylococcus epidermidis
}

\section{FORMULATION OF PATIKAN KEBO (Euphorbia hirta L.) EXTRACT GEL AND ACTIVITY TEST AGAINST Staphylococcus epidermidis}

\author{
Tri Novrianti Djanggola ${ }^{1}$, Yusriadi ${ }^{1}$, Muhamad Rinaldhi Tandah ${ }^{1 *}$ \\ ${ }^{1}$ Jurusan Farmasi, Fakultas MIPA, Universitas Tadulako, Palu, Indonesia
}

Received 30 Juli 2016, Accepted 1 September 2016

\begin{abstract}
ABSTRAK
Patikan kebo (Euphorbia hirta L.) merupakan salah satu tanaman yang memiliki aktivitas antibakteri terhadap bakteri Staphylococcus epidermidis, yang merupakan bakteri penyebab jerawat.Flavonoid dan tanin merupakan senyawa yang diduga berperan sebagai senyawa aktif antijerawat.Penelitian ini bertujuan untuk memformulasi sediaan gel ekstrak patikan kebo, menguji aktivitas antibakteri terhadap Staphylococcus epidermidis dengan metode difusi agar menggunakan pencadang kertas dan mengetahui stabilitas sediaan.Data aktivitas antibakteri yang diperoleh dianalisis dengan ANOVA one way dengan taraf kepercayaan 95\%, dilanjutkan dengan uji Duncan. Hasil penelitian menunjukkan sediaan gel ekstrak patikan kebo mempunyai aktivitas terhadap Staphylococcus epidermidis, dan terdapat perbedaan yang nyata antar sediaan terhadap aktivitasnya dalam menghambat bakteri tersebut, gel tidak memenuhi parameter stabilitas sediaan selama 28 hari penyimpanan
\end{abstract}

Kata kunci : Patikan kebo (Euphorbia hirta L), gel, antibakteri, Staphylococcus epidermidis

\begin{abstract}
Patikan kebo (Euphorbia hirta L.) is a plant that have activity of inhibiting the Staphylococcus epidermidis bacteria, which was known as the cause of acnes. Flavonoids and tannin as antibacterial compounds which supposedly can act as an active antiacne. Purposes of this research is formulating extract gel of patikan kebo and antibacterial activity against Staphylococcus epidermidis by agar difussion method using paper disc and to know stability of the gel. The result was analyzed by One Way ANOVA with confidence level of 95\%, followed by Duncan test. The result of this research showed test antibacterial activity that difference among the concentration extract has a noticeable difference zone of inhibition and extract gel of patikan kebo not have good physical quality during 28 days of storage.
\end{abstract}

Keywords : Patikan kebo (Euphorbia hirta L.), gel, antibacterial, Staphylococcus epidermidis

*) Coresponding Author : Muhamad Rinaldhi Tandah, prof.aldhi@gmail.com (ph:+62-852-4115-3050) 


\section{PENDAHULUAN}

Pada awal peradaban manusia, semua flora yang ada di muka bumi ini tumbuh secara liar.Gulma secara sederhana dapat diartikan sebagai tumbuhan liar, tumbuhan pengganggu atau tumbuhan yang tidak dikehendaki dan merugikan.Salah satu yang digolongkan ke dalam gulma yaitu patikan kebo. Patikan kebo memiliki nama ilmiah Euphorbia hirta yang tumbuh liar di daerah tropis di Indonesia. Seluruh bagian tanaman dapat digunakan sebagai obat (Kusuma, 2006).Keberadaan tanaman tersebut masih kurang mendapat perhatian oleh masyarakat padahal tanaman tersebut. Padahal tanaman tersebut memiliki banyak khasiat untuk mengobati beberapa penyakit seperti disentri, melancarkan kencing, abses pare dan bronchitis kronis, abses payudara, tipus abdominalis, dan eksim, radang ginjal, radang tenggorokan dan asma (Permadi, 2006). Selain itu patikan kebo juga memiliki khasiat sebagai antiinflamasi dan menghilangkan gatal (antipruritik) (Kusuma, 2006).Patikan kebo (Euphorbia hirta L.) terbukti menghambat pertumbuhan bakteri Staphylococcus epidermidisdengan Konsentrasi Hambat Minimum pada konsentrasi $10 \mathrm{mg} / \mathrm{mL}$ (Hamdiyanti, 2008).

Bakteri Propionibacterium acne dan Staphylococcus epidermidis merupakan salah satu penyebab berkembangnya lesi pada jerawat (Anonim, 2011).Staphylococcus epidermidis yaitu organisme aerobik biasanya terdapat pada infeksi superfisial di dalam kelenjar sebaceous.Dalam sebuah biofilm Staphylococcus epidermidis dilindungi terhadap serangan dan sistem kekebalan tubuh dan melawan perlakuan antibiotik yang membuat Staphylococcus epidermidis sulit dihentikan (Fitzpatrick et al, 2005).

Respons kulit sebagai suatu ciri kelamin sekunder selama masa pubertas, menggambarkan peningkatan kadar androgen dengan bertambahnya ukuran dan sekresi folikel sebasea dan sekresi kelenjar apokrin, manifestasi yang paling sering dijumpai adalah timbulnya jerawat (Behrman, 2000). Selama masa puber hormon-hormon bekerja sangat aktif, menyebabkan kulit memproduksi sebum secara berlebihan. Oleh sebab itu jerawat mulai muncul ketika pori-pori kulit tersumbat oleh minyak tersebut, yang sebenarnya berfungsi meminyaki kulit dan rambut, karena kelenjar yang menghasilkan minyak banyak terdapat di dahi, hidung, dagu maka area ini merupakan tempat yang paling mudah berjerawat (Utami, 2009).

Saat ini telah banyak digunakan pengobatan jerawat dengan menggunakan antibiotik seperti tetrasiklin, eritromisin, doksisiklin dan klindamisin.Studi sebelumnya yang dilakukan Dreno (2007) telah meneliti peningkatan resistensi antibiotik eritromisin pada 40 pasien jerawat ringan sampai yang cukup parah.Penelitian tersebut menunjukkan bahwa prevalensi resistensi bakteri terhadap eritromisin yaitu $95 \%$ pada bakteri Staphylococcus epidermidis dan 52\% pada bakteri Propionibacterium acne, dimana strain yang lebih resisten pada pasien dengan lesi didominasi inflamasi (Papula dan pustula). Untuk mengatasi resistensi antibiotik tersebut maka tanaman yang memiliki aktivitas antibakteri dan antiinflamasi dapat digunakan sebagai alternatif pada pengobatan infeksi dan peradangan pada jerawat, sehingga perlu dibuat sediaan yang aman, nyaman dan praktis untuk digunakan pada pengobatan jerawat. Salah satu sediaan yang paling banyak digemari yaitu gel, karena gel memiliki kandungan air yang tinggi sehingga memberikan efek mendinginkan pada kulit.Gel yang stabil yaitu gel yang stabil selama penyimpanan dan saat dikeluarkan dari tube (Zatz, 1996). Selain itu segi organoleptik, pH dan viskositas tetap bertahan selama batas waktu yang telah ditentukan.Dalam penelitian ini melihat apakah patikan kebo dapat diformulasi menjadi sediaan gel serta melihat stabilitas fisik gel dan aktivitas antibakterinya sebelum dan sesudah formulasi. 


\section{METODE PENELITIAN}

\section{Waktu dan Tempat Penelitian}

Penelitian ini mulai dilakukan dari bulan Juli sampai dengan September 2013 di Laboratorium Fitokimia dan Laboratorium Mikrobiologi, Program Studi Farmasi, Fakultas Matematika dan Ilmu Pengetahuan alam, Universitas Tadulako Palu.

\section{Alat dan Bahan}

Alat

Alat yang digunakan antara lain seperti, wadah maserasi, rotavapor (Haake D), timbangan analitik (Mettler AE 200), penangas air, autoklaf (Fison), inkubator (Memmert), laminary airflow cabinet (Astec HLF 1200 L), oven (Gallenkamp), $\mathrm{pH}$ meter (Trans Instrumen), viskometer Brookfield, lemari pendingin, ose, bunsen, mikropipet (Eppendorf), alat-alat gelas, pipet tetes mortir, stamper, jangka sorong, cawan petri.

\section{Bahan}

Ekstrak etanol patikan kebo, karbomer 940, trietanolamin, propilenglikol, gliserin, sodium metabisulfit, metil paraben, etanol (tekhnis), air suling, DMSO, Nutrien Agar (NA), glukosa, kapas steril, aluminium foil, paper disk.

\section{Pengambilan dan Identifikasi Sampel}

Sampel yang digunakan adalah patikan kebo (Euphorbia hirta L.) yang diperoleh dari desa Mpanau, Kabupaten Sigi Biromaru, Sulawesi Tengah. Sampel terlebih dahulu disortasi basah kemudian dicuci pada air yang mengalir, setelah itu patikan kebo dilakukan proses perajangan agar diperoleh ukuran yang lebih kecil. Untuk menghilangkan kandungan air pada tumbuhan dilakukan pengeringan dengan cara diangin-anginkan, lalu disortasi kering, dibuat menjadi serbuk kasar dan disimpan.

Identifikasi tumbuhan patikan kebo dilakukan di UPT. Sumber Daya Hayati Sulawesi, Universitas Tadulako.

\section{Pengolahan Sampel}

Serbuk kasar patikan kebo dilakukan proses ekstraksi yaitu dengan cara merendam sebanyak 600 gram dengan pelarut $4000 \mathrm{ml}$ etanol 96\%, dihomogenkan dan dimaserasi selama 3 hari dengan sesekali pengadukan. Kemudian disaring menggunakan kertas saring sehingga diperoleh filtrat.Filtrat diuapkan dengan penguap berputar (rotavapor) dengan suhu $69^{\circ} \mathrm{C}$ sampai pelarutnya sudah tidak menetes sehingga dihasilkan ekstrak kental.

\section{Pembuatan Media Uji}

Nutrient Agar (NA) sebanyak 20 gram dan glukosa sebanyak 10 gram dilarutkan dengan aquades (30 $\mathrm{g} / 1000 \mathrm{ml})$ menggunakan erlenmeyer. Setelah itu dihomogenkan dengan stirer di atas penangas air sampai mendidih. Sebanyak $5 \mathrm{ml}$ dituangkan masing-masing pada 3 tabung reaksi steril dan ditutup dengan aluminium foil. Media tersebut disterilkan dalam autoklaf pada suhu $121^{\circ} \mathrm{C}$ selama 15 menit, kemudian dibiarkan pada suhu ruangan selama \pm 30 menit sampai media memadat pada kemiringan $30^{\circ}$. Media agar miring digunakan untuk inokulasi bakteri.

\section{Pembuatan Stok Kultur Bakteri}

Satu koloni bakteri Staphylococcus epidermidis diambil dengan jarum ose steril, lalu diinokulasikan pada permukaan media GNA dengan cara menggores, kemudian diinkubasikan pada suhu $37^{\circ} \mathrm{C}$ selama 24 jam.

\section{Pembuatan Inokulum Bakteri}

Koloni bakteri Staphylococcus epidermidis diambil dari stok kultur diambil menggunakan jarum ose steril, kemudian disuspensikan ke dalam $10 \mathrm{ml}$ larutan $\mathrm{NaC} 1$ $0,9 \%$ steril lalu diinkubasikan pada suhu $37^{\circ} \mathrm{C}$ sampai mencapai kekeruhan yang sama dengan standar kekeruhan McFarland.

\section{Aktivitas Antibakteri Ekstrak}

Biakan bakteri Staphylococcus epidermidis diambil sebanyak $0,1 \mathrm{ml}$ lalu ditambahkan media NA + glukosa steril yang masih hangat sebanyak $15 \mathrm{ml}$ dimasukkan ke dalam cawan petri kemudian dihomogenkan dan dibiarkan memadat, lalu paper disk (diameter $3 \mathrm{~mm}$ ) yang telah direndam pada masing-masing konsentrasi ekstrak dan kontrol selama 15 menit ditempelkan pada masing-masing cakram, lalu diinkubasi pada suhu $37^{\circ} \mathrm{C}$ selama 24 jam. Pengukuran zona hambat yang terbentuk di sekeliling cakram menggunakan mistar atau jangka sorong. 


\section{Djanggola et al./Galenika Journal of Pharmacy}

\section{Pembuatan Sediaan Gel}

Sediaan gel yang dibuat sebanyak $200 \mathrm{~g}$. Karbomer 940 didispersikan pada $50 \mathrm{ml}$ air menggunakan stamper dengan cara digerus kemudian ditambahkan sejumlah ekstrak dilarutkan dengan gliserin, di tambahkan triethanolamin dan propilenglikol digerus hingga homogen. Metil paraben dan natrium metabisulfit dilarutkan dalam air panas sebanyak $15 \mathrm{ml}$, ditambahkan ke dalam massa gel dan terus digerus sampai homogen. Sisa air ditambahkan sampai 200 g sambil terus digerus hingga gel homogen, lalu dimasukkan ke dalam wadah.

Tabel 1. Komposisi Formula Gel Ekstrak Patikan Kebo

\begin{tabular}{|l|c|c|c|c|c|}
\hline \multirow{2}{*}{ Nama Bahan } & \multicolumn{5}{|c|}{ Konsentrasi (\%) } \\
\cline { 2 - 6 } & F1 & F2 & F3 & F4 & F5 \\
\hline Ekstrak patikan kebo & 0,4 & 0,6 & 0,8 & 1 & 3 \\
Carbomer 940 & 0,7 & 0,7 & 0,7 & 0,7 & 0,7 \\
Trietanolamin & 0,6 & 0,6 & 0,6 & 0,6 & 0,6 \\
Propilenglikol & 15 & 15 & 15 & 15 & 15 \\
Gliserin & $\mathbf{8}$ & 8 & 8 & 8 & 8 \\
Natrium Metabisulfit & 0,05 & 0,05 & 0,05 & 0,05 & 0,05 \\
Metil paraben & 0,2 & 0,2 & 0,2 & 0,2 & 0,2 \\
Air & Secukupnya & secukupnya & secukupaya & secukupaya & Socukupnya \\
\hline
\end{tabular}

\section{Aktivitas Antibakteri Formula}

Sebanyak 0,1 $\mathrm{ml}$ inokulum dimasukkan ke dalam cawan petri steril, setelah itu dituang media glukosa nutrien agar sebanyak $20 \mathrm{ml}$ dengan suhu $45-50^{\circ} \mathrm{C}$, selanjutnya media dihomogenkan dengan cara digoyang di atas permukaan meja agar media dan suspensi bakteri tercampur rata. Pada media yang telah setengah padat diletakkan beberapa paper disk, dipipet $0,1 \mathrm{ml}$ gel ekstrak patikan kebo yang telah dilarutkan dengan DMSO lalu dimasukkan ke dalam pencadang kertas, kemudian diinkubasi dalam inkubator pada suhu $37^{\circ} \mathrm{C}$ selama 24 jam, setelah itu diukur diameter daerah hambatan (zona jernih) pertumbuhan di sekitar paper disk dengan menggunakan jangka sorong.

\section{Stabilitas Fisik Sediaan}

Pemeriksaan organoleptik dilakukan dengan mengamati perubahan-perubahan bentuk, warna, dan bau dari sediaan dan sediaan standar selama waktu penyimpanan, pengamatan perubahan bentuk, warna dan bau tersebut dilakukan setiap sekali dalam seminggu sampai hari ke-30 penyimpanan.

\section{Homogenitas Sediaan}

Dioleskan gel di atas kaca objek dan diratakan.Diamati homogenitas sediaan dipermukaan kaca objek.

\section{pH Sediaan}

Pengukuran $\mathrm{pH}$ dilakukan dengan cara mencelupkan katoda $\mathrm{pH}$ meter ke dalam sediaan gel, $\mathrm{pH}$ sediaan akan tertera pada monitor. Data pengukuran dilakukan setiap sekali dalam seminggu sampai hari ke 30 penyimpanan.

\section{Viskositas Sediaan}

Pengujian viskositas sediaan menggunakan viskometer Brookfield, dengan mencelupkan spindel no.6 ke dalam sediaan. Data yang diperoleh akan tertera pada monitor.

\section{HASIL DAN PEMBAHASAN Hasil}

Identifikasi tumbuhan yang dilakukan di Upt. Sumber Daya Hayati Sulawesi, Universitas Tadulako menyatakan bahwa tumbuhan yang digunakan dalam penelitian ini adalah patikan kebo (Euphorbia hirta L), famili Euphorbiaceae. Diperoleh dari desa Mpanau, Kabupaten Sigi Biromaru, Sulawesi Tengah.

Simplisia patikan kebo sebanyak 600 gram diekstraksi dengan metode maserasi menggunakan pelarut etanol $96 \%$ sebanyak 4 Liter. Hasil ekstrak kental etanol patikan kebo yaitu 67,57 gram. Rendamen yang diperoleh yaitu $11,261 \%$.

Hasil uji aktivitas terhadap Staphylococcus epidermidis menunjukkan bahwa ekstrak etanol patikan kebo dapat menghambat pertumbuhan Staphylococus epidermidis. Semakin tinggi konsentrasi ekstrak akan menghasilkan diameter daerah hambat yangsemakin besar. Hasil pengukuran diameter daerah hambat ekstrak etanol patikan kebo dapat dilihat pada Tabel 2 berikut. 


\section{Djanggola et al./Galenika Journal of Pharmacy}

Tabel 2. Hasil Uji Aktivitas Antibakteri Ekstrak Patikan kebo Terhadap Staphylococus epidermidis

\begin{tabular}{|c|c|}
\hline \multirow{2}{*}{$\begin{array}{c}\text { Konsentrasi ekstrak } \\
(\mathrm{mg} / \mathrm{ml})\end{array}$} & $\begin{array}{c}\text { Diameter daerah } \\
\text { hambatan }(\mathrm{mm})\end{array}$ \\
\cline { 2 - 2 } & $\mathrm{D}^{*}$ \\
\hline 4 & 11,00 \\
\hline 6 & 14,21 \\
\hline 8 & 14,96 \\
\hline 10 & 17,68 \\
\hline 30 & 19.00 \\
\hline $\mathrm{K}(-)$ & $0^{*}$ \\
\hline
\end{tabular}

Keterangan: $\mathrm{D}^{*}=$ rata-rata 3 kali pengulangan * = tidak ada hambatan

Hasil pemeriksaan stabilitas dilakukan terhadap sediaan gel ekstrak etanol patikan kebo dilakukan pada lima formula: F 1 (Formula mengandung 0,4\% ekstrak), P2 (Formula mengandung $0,6 \%$ ekstrak) F3 (Formula mengandung 0,8\% ekstrak), F4 (Formula mengandung 1\% ekstrak) dan F5 (Formula mengandung 3\% konsentrasi ekstrak) dengan melihat perubahan konsistensi, warna dan bau. Pemeriksaan dilakukan secara visual pada suhu kamar selama 30 hari dengan rentang waktu pemeriksaan 7 hari. Hasil dapat dilihat pada Tabel 3 berikut.

Tabel 3. Data Pengamatan perubahan bentuk, warna dan bau sediaan

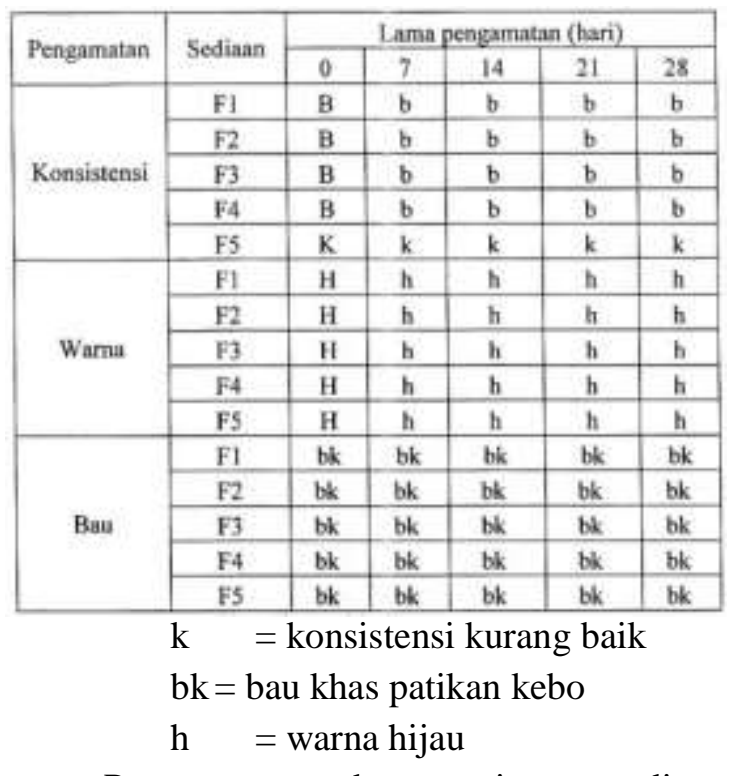

Pengamatan homogenitas sediaan dilakukan dengan cara mengoleskan sejumlah tertentu sediaan pada dua kaca objek. Hasil dapat dilihat pada Tabel 4 berikut.

Tabel 4. Data pengamatan homogenitas sediaan

\begin{tabular}{|c|c|c|c|c|c|}
\hline \multirow{2}{*}{ Sediaan } & \multicolumn{5}{|c|}{ Lama pengamatan (hari) } \\
\cline { 2 - 6 } & 0 & 7 & 14 & 21 & 28 \\
\hline F1 & H & H & h & h & h \\
\hline F2 & H & H & h & h & h \\
\hline F3 & H & H & h & h & h \\
\hline F4 & H & h & h & h & h \\
\hline F5 & H & h & h & h & h \\
\hline
\end{tabular}

Keterangan: $\mathrm{h}=$ homogen

Pengukuran $\mathrm{pH}$ sediaan dilakukan menggunakan $\mathrm{pH}$ meter selama 30 hari penyimpanan dengan rentang waktu permeriksaan selama 7 hari.

Tabel 5. Data pengukuran $\mathrm{pH}$

\begin{tabular}{|c|c|c|c|c|c|c|}
\hline \multirow{2}{*}{$\begin{array}{c}\text { Waktu } \\
\text { penyimpanan } \\
\text { (hari) }\end{array}$} & \multicolumn{7}{|c|}{ Sediaan } \\
\cline { 2 - 7 } & $F 1$ & $F 2$ & $F 3$ & $F 4$ & F5 & $\begin{array}{c}\text { Koatrol } \\
(-)\end{array}$ \\
\hline 0 & 6.60 & 6.40 & 6.24 & 6.30 & 6.07 & 6.95 \\
\hline 7 & 7.34 & 6.72 & 6.42 & 6.66 & 6.45 & 7.57 \\
\hline 14 & 6.36 & 5.61 & 5.90 & 6.04 & 5.70 & 7.64 \\
\hline 21 & 6.41 & 5.77 & 6.03 & 6.13 & 5.75 & 7.69 \\
\hline 28 & 6.49 & 5.72 & 6.0 & 6.08 & 5.71 & 7.64 \\
\hline
\end{tabular}

Penentuan viskositas sediaan dilakukan selama 28 hari penyimpanan dengan selang waktu pengukuran 7 hari dengan menggunakan viskometer-Brookfield, dengan spindel 6 dan kecepatan $2 \mathrm{rpm}$. Hasil dapat dilihat pada tabel 6 berikut.

Tabel 6. Data viskositas sediaan

\begin{tabular}{|c|c|c|c|c|c|c|}
\hline \multirow{2}{*}{$\begin{array}{c}\text { Waktu } \\
\text { penyimpanan } \\
\text { (hari) }\end{array}$} & \multicolumn{7}{|c|}{ Viskositas sediaan (Cp) } \\
\hline & $F 1$ & $F 2$ & $F 3$ & $F 4$ & $F 5$ & Kontrol (-) \\
\hline 0 & 8925 & 7317 & 7320 & 6100 & 2720 & 9980 \\
\hline 7 & 9570 & 6500 & 5900 & 3240 & 2544 & 9960 \\
\hline 14 & 7387 & 7080 & 5620 & 5160 & 2660 & 9400 \\
\hline 21 & 7483 & 7340 & 6840 & 5320 & 4880 & 10320 \\
\hline 28 & 5961 & 5000 & 5140 & 4920 & 2120 & 10680 \\
\hline
\end{tabular}

Uji aktivitas antibakteri sediaan gel ekstrak patikan kebo dilakukan pada 5 formula dengan replikasi sebanyak 3 kali menggunakan metode difusi agar terhadap bakteri Staphylococcus epidermidis. Hasil dapat dilihat pada Tabel 7 berikut ini. 
Tabel 7.Hasil uji aktivitas antibakteri gel ekstrak patikan keboterhadap Staphylococcus epidermidis

\begin{tabular}{|c|c|c|c|c|c|c|}
\hline \multicolumn{7}{|c|}{ Diameter daerah hambatan (mm) } \\
\hline F1 & F2 & F3 & F4 & F5 & Kontrol $(-)$ & Kontrol $(+)$ \\
\hline 6,93 & 9,56 & 10,3 & 11,3 & 15,0 & $0^{*}$ & 32,0 \\
\hline
\end{tabular}

Keterangan: $*$ = tidak ada hambatan

Berdasarkan hasil penelitian menggunakan analisis statistik melalui softwarestatistik, diketahui terdapat perbedaan yang nyata antara konsentrasi ekstrak dalam sediaan terhadap diameter hambat Staphylococcus epidermidis. Dan hasil uji One-Way ANOVA didapatkan nilai signifikan sebesar 0,000 ( $\mathrm{p}<0,05)$. Hal ini berarti bahwa perubahan konsentrasi ekstrak dalam sediaan memberikan perbedaan yang nyata terhadap diameter hambat bakteri pada taraf kepercayaan 95\%. Pada output tabel uji Duncan, konsentrasi 0,4\% memiliki perbedaan yang nyata terhadap konsentrasi $0,6 \%$, konsentrasi $0,6 \%$ dan $0,8 \%$ tidak memberikan perbedaan yang nyata, sedangkan konsentrasi $0,8 \%$ memberikan perbedaan yang nyata terhadap konsentrasi $1 \%$, dan konsentrasi $1 \%$ memberikan perbedaan yang nyata terhadap konsentrasi $3 \%$.

\section{Pembahasan}

Penelitian ini merupakan penelitian eksperimental yang dimaksudkan untuk mengetahui efek antibakteri ekstrak patikan kebo (Euphorbia hirta L.) yang telah diformulasi menjadi salah satu sediaan farmasi menggunakan metode difusi agar. Dengan metode ini pada jarak tertentu pada masingmasing cakram antibiotik terdifusi sampai pada titik antibiotik tersebut tidak lagi menghambat pertumbuhan mikroba yang ditunjukkan sebagai area jernih atau bersih yang mengelilingi tempat zat dengan aktivitas antimikroba (Harmita, 2006). Selain itu juga dalam penelitian ini dapat diketahui hubungan antara konsentrasi ekstrak etanol patikan kebo pada gel terhadap aktivitas pertumbuhan bakteri.

Hasil uji aktivitas pada ekstrak patikan kebo menunjukkan korelasi positif yaitu semakin tinggi konsentrasi ekstrak maka semakin besar pula diameter hambat bakteri. Cakram kertas yang telah mengandung bahan uji dan telah ditanam pada media perbenihan agar padat yang telah dicampur dengan suspensi bakteri akan berdifusi ke dalam media tersebut, maka terbentuklah zona hambat (zona bening) tersebut di sekitar cakram. Pada penelitian sebelumnya diameter hambat patikan kebo dengan KHM 1\% memiliki diameter hambat 7,67 $\mathrm{mm}$ (Hamdiyanti, 2008). Jika dibandingkan pada Tabel 2 menunjukkan konsentrasi 1\% diameter hambatannya sebesar 17,68 dan konsentrasi terkecil yaitu $0,4 \%(4 \mathrm{mg} / \mathrm{mL})$ masih memiliki aktivitas penghambatan dengan rata-rata diameter zona hambat yaitu $11,00 \mathrm{~mm}$. Perbedaan ukuran zona hambatan tersebut dipengaruhi oleh bagian tumbuhan yang digunakan dimana penelitian sebelumnya menggunakan bagian daun, sedangkan penelitian ini menggunakan bagian daun, batang dan akar, selain itu dapat dipengaruhi oleh kepadatan atau viskositas media biakan, kecepatan difusi antibiotik, konsentrasi antibiotik pada cakram filter, sensitifitas organisme terhadap antibiotik dan interaksi antibiotik dengan media (Harmita, 2006).

Sediaan yang dibuat pada penelitian ini yaitu gel. Gel merupakan salah satu sediaan yang banyak digemari karena kandungan airnya yang tinggi. Gel yang mengandung ekstrak etanol patikan kebo yang akan diuji pada Staphylococcus epidermidis yaitu salah satu bakteri penyebabjerawat. Jerawat merupakan salah satu masalah yang hampir semua dialami oleh kaum remaja pada khususnya.Patikan kebo terlebih dulu diekstraksi dengan tujuan untuk menarik komponen kimia yang terdapat di dalam simplisia menggunakan pelarut etanol dengan konsentrasi 96\%. Etanol dengan konsentrasi demikian dapat lebih mudah berpenetrasi ke dalam sel serta bersifat universal yang mampu menarik semua jenis zat aktif, baik bersifat polar, semi polar dan non polar dan kadar toksisitasnya rendah (Anonim, 1986). 
Karbomer dipilih sebagai salah satu bahan dasar gel yang akan mengembang jika didispersikan dalam air (Lachman, 2008) dan dengan penambahan triethanolaminakan meningkatkan viskositas pada sediaan gel (Kibbe, 2000) selain itu juga mencegah rusaknya dispersi dari karbopol ketika terpapar cahaya sehingga gel tetap bening.

Evaluasi kestabilan sediaan gel sebelum dan sesudah penyimpanan dilakukan untuk menentukan kestabilan secara fisik karena evaluasi merupakan salah satu parameter untuk mendeteksi ketidakstabilan dari gel. Stabilitas fisik gel dengan konsentrasi ekstrak Fl $(0,4 \%)$, F2 (0,6\%), F3 (0,8\%), F4 (1\%) dan F5 (3\%) selama penyimpanan secara keseluruhan tetap memiliki bau khas ekstrak patikan kebo dan warna hijau dari penambahan ekstrak. Konsistensi Fl, F2, F3, F4 memiliki konsistensi yang baik sedangkan pada F5 memiliki konsistensi yang kurang, hal ini terlihat dari teksturnya yang sedikit encer. Hal ini disebabkan karena ekstrak memiliki tekstur yang encer sehingga pada saatdimasukkan kedalam basis gel yang kental mengakibatkan gel yang mengandung ekstrak konsistensinya semakin encer.

Berdasarkan hasil analisis t-student terhadap $\mathrm{pH}$ sediaan, terlihat bahwa semua sediaan menunjukkan perbedaan $\mathrm{pH}$ yang nyata selama penyimpanan pada hari 0 sampai hari ke-28 pada suhu kamar $\left(30^{\circ} \mathrm{C}\right)$. Tingkat keasaman $(\mathrm{pH})$ fisiologis kulit yaitu antara 4,5 - 6,5 (Tranggono \& Latifah, 2007). Mengacu pada nilai $\mathrm{pH}$ tersebut, sediaan gel ekstrak patikan kebo memenuhi syarat sebagai sediaan kosmetik.Analisis t-student terhadap nilai viskositas sediaan juga menunjukkan bahwa selama penyimpanan semua sediaan memiliki perbedaan yang nyata terhadap viskositasnya selama 28 hari penyimpanan.Hal tersebut menunjukkan bahwa sediaan gel ekstrak patikan kebo tersebut tidak stabil selama penyimpanan.

Pemeriksaan homogenitas tidak memperlihatkan adanya butir-butir kasar atau partikel di dalam gel serta terdapat persamaan warna yang merata, sehingga dapat disimpulkan sediaan tersebut homogen dan pada saat dioleskan sediaan tidak meninggalkan bekas warna hijau dari gel tersebut.

Dari hasil pengujian aktivitas antibakteri sediaan gel memiliki zona hambat yang berbeda-beda.Semakin besar jumlah ekstrak yang dimasukkan ke dalam basis gel maka semakin besar pula diameter hambatannya.Hal tersebut karena jumlah ekstrak yang terdapat pada sediaan berbanding lurus terhadap besamya daerah difusi.

\section{DAFTAR PUSTAKA}

Anonim, (1986). Sediaan Galenik. Departemen Kesehatan Republik. Indonesia. Jakarta.

Anonim. (2011). Farmakope Herbal Indonesia : Suplemen II Edisi I. Departemen Kesehatan Republik Indonesia, Jakarta.

Behrman, dkk. (2000). Ilmu Kesehatan Anak Nelson. Volume 3. EGC, Jakarta.

Dreno.et al, (2007). Erythromycin-resistance of cutaneous bacterial flora in acne. European Journal of Dermatology, 11(6), 549-553.

Fitzpatrick.et al, (2005). Evidence for ica ADBC-Independent Biofilm Development Mechanism In Methicillin-Resistant Staphylococcus Aureus Clinical Isolates. J Clin Microbiology, 43(4), 1973-1976.

Hamdiyanti. (2008). Aktivitas Antibakteri Ekstrak Daun Patikan Kebo (Euphorbia hirta) Terhadap Pertumbuhan Bakteri Staphylococcus epidermidis. Jurnal Teori Dan Hasil Penelitian Pembelajaran MIPA, Jurusan Pendidikan Biologi FMIPA UI, 12(12).

Harmita. dkk. (2006). Buku Ajar Analisis Hayati, Edisi 3. Buku Kedokteran EGC, Jakarta. 


\section{Djanggola et al./Galenika Journal of Pharmacy}

Kibbe. (2000). Handbook of Pharmaceutical Excipients, $3^{\text {rd }}$ edition. The Pharmaceutical Press, London.

Kusuma. (2006). Tumbuhan Liar Berkhasiat Obat. Agro Media Pustaka, Jakarta.

Lachman, L., Lieberman, HA., \& Kanig, J.L. (2007). Teori dan Praktek Farmasi Industri. UI Press, Jakarta.

Permadi. (2006). Tanaman Obat Pelancar Air Seni. Penebar Swadaya, Depok.
Tranggono \& Latifah. (2007). Buku Pegangan Ilmu Pengetahuan Kosmetik. Gramedia Pustaka, Jakarta

Utami. (2009). Bebas Masalah Kulit. Med Express. Penerbit Kanisius, Yogyakarta.

Zatz. (1996). Gels. In : H.A Lieberman. Pharmaceutical Dossage Forms Disperse System. Marcell Dekker Inc, New York. 